\title{
A COMPARATIVE ANALYSIS OF PREVALENCE OF PSYCHIATRIC MORBIDITIES IN METABOLIC SYNDROME PATIENTS
}

\author{
R. Priya Dharshini ${ }^{1}$, P. Hariharan², W. J. Alexander Gnanadurai ${ }^{3}$, R. Saravana Jothi ${ }^{4}$, M. Mohammed Ilyas Rahamatholla ${ }^{5}$, \\ D. Punithavathi ${ }^{6}$, Nileena N. K. $M^{7}$
}

\begin{abstract}
1 Junior Resident, Department of Psychiatry, Government Stanley Medical College, Chennai. ${ }^{2}$ Assistant Professor, Department of Psychiatry, Government Stanley Medical College, Chennai. 3 Professor and HOD, Department of Psychiatry, Government Stanley Medical College, Chennai. ${ }^{4}$ Associate Professor, Department of Psychiatry, Government Stanley Medical College, Chennai. ${ }^{5}$ Assistant Professor, Department of Psychiatry, Government Stanley Medical College, Chennai. 6Junior Resident, Department of Psychiatry, Government Stanley Medical College, Chennai. Junior Resident, Department of Psychiatry, Government Stanley Medical College, Chennai.
\end{abstract}

\section{ABSTRACT}

\section{BACKGROUND}

Metabolic syndrome is by definition a multisystem disorder. Metabolic syndrome, Syndrome X and Insulin resistance syndrome are all terms coined to describe the recognised clustering of metabolic and cardiovascular abnormalities including abnormalities of glucose homeostasis (insulin resistance, glucose intolerance or diabetes mellitus), obesity, hypertension and dyslipidaemia.

The aim of this study is to compare prevalence of psychiatric morbidities like depression and anxiety in Metabolic syndrome patients.

\section{MATERIALS AND METHODS}

This is a case-control study done in 50 patients of metabolic syndrome and 50 controls in a tertiary care setting in urban region in Tamilnadu from 2015 - 2016 for a period of 6 months. The Metabolic Syndrome is screened using standardised clinical and laboratory parameters and National Cholesterol Education Program- Adult Treatment Panel 3 (NCEP-ATP 3) and anxiety and depression were measured in the cases and control using Hamilton Rating Scale for Anxiety (HAM-A) and Beck Depression Inventory (BDI).

\section{RESULTS}

Metabolic Syndrome was associated with Depression and Anxiety and the participants with Metabolic Syndrome had high score of Depression (40\%) and Anxiety (14\%) than control group score for Depression (34\%) and Anxiety (10\%), and there is a significant relationship of Depression and Anxiety in Metabolic syndrome patient than control group. The ' $\mathrm{P}$ ' value for Depression is 0.008 and the ' $\mathrm{P}$ ' value for Anxiety is 0.012 .

\section{CONCLUSION}

The study shows an association between Metabolic Syndrome and Depression and Anxiety in heterogeneous sample. The presence of Depression and Anxiety in individuals with Metabolic Syndrome has implications for clinical management.

\section{KEYWORDS}

Metabolic Syndrome, Depression and Anxiety.

HOW TO CITE THIS ARTICLE: Dharshini RP, Hariharan P, Gnanadurai WJA, et al. A comparative analysis of prevalence of psychiatric morbidities in metabolic syndrome patients. J. Evolution Med. Dent. Sci. 2017;6(61):4498-4502, DOI: $10.14260 /$ Jemds/2017/972

\section{BACKGROUND}

Metabolic syndrome is by definition a multisystem disorder. Metabolic syndrome, Syndrome $\mathrm{X}$ and Insulin resistance syndrome are all terms coined to describe the recognised clustering of metabolic and cardiovascular abnormalities including abnormalities of glucose homeostasis (insulin resistance, glucose intolerance or diabetes mellitus), obesity, hypertension and dyslipidaemia.

Financial or Other, Competing Interest: None.

Submission 13-06-2017, Peer Review 20-07-2017,

Acceptance 26-07-2017, Published 31-07-2017.

Corresponding Author:

Dr. P. Hariharan,

Assistant Professor,

Department of Psychiatry,

Government Stanley Medical College,

Chennai.

E-mail: drhariharan@yahoo.com

DOI: $10.14260 /$ jemds $/ 2017 / 972$

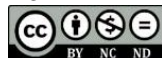

At present the metabolic syndrome appears to be precipitated by multiple underlying risk factors rather than a single cause. Abdominal obesity and insulin resistance are the most important risk factors. ${ }^{(1,2)}$

NHANES (National Health and Nutrition Examination Survey) 1999 - 2006 reported a metabolic syndrome prevalence of $34 \%$.(3) It has been estimated that $20 \%-25 \%$ of South Asians have developed metabolic syndrome and many may be prone to it.(4) The scientific interest is that factors defining the syndrome are all factors associated with increased mortality and morbidity, both in physical and mental health.

Metabolic syndrome and psychiatric morbidities such as depression and anxiety are common. They are likely to coexist, but importantly either one is known to worsen the other. Psychological stress after the diagnosis of metabolic syndrome may worsen hyperglycaemia, blood pressure levels initiated by hypothalamic-pituitary-adrenal axis.(5) Identifying co-morbid psychiatric conditions is crucial to 
reduce the disability of metabolic syndrome. However, it has been noted that in some situations psychiatric illnesses are under-recognised by physicians, because of a wrong consideration of psychiatric morbidities (Depression, Anxiety) as a "normal consequences of difficult medical illnesses" (Lustman, et al).(6)

In India, metabolic syndrome prevalence is common after the age of 20 with prevalence rate of $20 \%$. In large crosssectional survey on urban Indians, the Chennai urban rural epidemiology study, the prevalence of metabolic syndrome was found to be $23 \%, 18 \%, 26 \%$ using WHO, ATP III, IDF definitions respectively.(7)

Identification and management of psychiatric morbidities in metabolic syndrome patients may have a favourable outcome on good glycaemic control, blood pressure, lipid profile and even prevents or postpones the metabolic syndrome related complications. So it is necessary to study psychiatric morbidity like depression, anxiety in metabolic syndrome patients elaborately.

\section{Aims and Objectives}

- To estimate the prevalence of psychiatric morbidities like depression and anxiety in Metabolic syndrome patients.

- To estimate the prevalence of psychiatric morbidities like depression and anxiety in Control group.

- To compare the prevalence of psychiatric morbidities like depression and anxiety in Metabolic syndrome and Control group.

\section{MATERIALS AND METHODS}

This is a retrospective, observational and comparative study.

\section{Inclusion Criteria}

- Patients diagnosed as Metabolic syndrome by Criteria of NCEP-ATP 3.

- Age $>30$ and < 50 years and registered in Diabetology Department.

- Patients with regular followup for the past 6 months.

- Consenting age related non-metabolic syndrome individuals accompanying with patients attending Diabetology outpatient department.

- Informed consent.

\section{Exclusion Criteria}

- Presence of other chronic illnesses like TB, bronchial asthma, hypothyroidism, cancer, connective tissue disorder or with history of myocardial infarction.

- Past or present history of any mental illness.

- Family history of any mental illness.

- Patients on drugs for the metabolic syndrome (Antipsychotics, steroids, antidepressants and antiepileptics).

\section{Materials for the Assessment}

- Socio-demographic proforma sheet designed for this study.

- Diagnostic criteria of Metabolic syndrome by Criteria NCEP-ATP 3.

- $\quad$ Beck Depression Inventory (BDI).(8)

\section{- Hamilton rating scale for Anxiety (HAM-A).(9)}

\section{Study Design}

After obtaining Ethical Committee approval, the study was conducted in Stanley Medical College and Hospital.

The study subjects (Cases) were taken from the Diabetology Department OP section, at Government Stanley Medical College Hospital. We took a sample size of 50, because the prevalence of metabolic syndrome is $35 \%$.

So, we took 46 cases and controls with a $5 \%$ of error and it was rounded to 50 in each group. Those who fulfilled the criteria of both inclusion as well as the exclusion criteria were included for this study. An informed consent was explained and obtained from the patients. A thorough clinical evaluation was done to find out any physical complications, psychiatric illnesses, any drug treatments, since these factors are the confounding factors of this study. Patients OP records were evaluated to obtain a glycaemic control status, hypertension status, waist circumference measured, complication, duration and age of onset.

An Age matched study subjects (Controls) were taken from the Diabetology Department OP section, at Government Stanley Medical College Hospital. The control group population were individuals (Attenders/ relatives) accompanying with the patients attending the Diabetology Outpatient Department. An informed consent was explained and obtained from them. A thorough clinical evaluation was done to find out any physical conditions, psychiatric illnesses, any drug treatments since these factors are the confounding factors of this study.

\section{Assessment Procedure of the Study}

Detailed socio-demographic details like age, sex, education, religion, socio-economic status, etc. were recorded in the semi-structured proforma sheet designed for this study. Patients as well as the control group individuals were evaluated clinically and the records of them were reviewed thoroughly. Diabetologist guidance was utilised when there was any doubt regarding the patient's (Case) disease status. Those who fulfilled the criteria of both inclusion as well as the exclusion criteria were screened and the interview was done to identify the depression and anxiety by using BDI (Beck Depression Inventory) and HAM-A (Hamilton Rating Scale for Anxiety).

\section{Beck's Depression Inventory (BDI)}

BDI is the one of the most important self-report rating scale, which is a gold standard tool to assess the depression severity. BDI was developed by Beck et al and his original consists of 21 items, which concern about various symptoms with varying degrees of severity and rated the scores as $0-3$. BDI-II edition was released after the introduction of DSM-IV, which included some new items and excluded some items present in the previous scale and make it more reflective. BDI-II consists of 21 items with a total score-ranges of $0-84$. Scores of 0 - 10 considered as normal mood swings, 45 and down considered as normal according to the scores, classified as mild-to-extreme depression. BDI was used in various studies because of its high reliability and consistent validity, and also the internal consistency of this scale is higher. 


\section{Hamilton Rating Scale for Anxiety (HAM-A)}

This scale is clinician administered with semi-structured type. This scale evaluates symptoms alone for anxiety disorders and not for any specific disorders. It is one of the rating scales developed first to assess the severity of the symptoms. Still it is used for clinical studies and for research purposes, because of its high reliability as well as its high validity. It also yields a high consistency. This scale consists of fourteen entities, each of the entity is graded as 0 to 4 (not present to severe), higher the scores more severe is the anxiety symptoms. The total score ranges from $0-56$ and the scores $<17$ indicates mild severity, scores between 18 and 24 indicates mild-to-moderate severity, scores between 25 and 30 indicates moderate-to-severe anxiety symptoms, and the total scores more than 30 indicates very severe. HAM-A scale is a simple scale easy to administer within 20 to 30 minutes. This scale has acceptable inter-rater reliability.

Statistical analysis will be done using computerised software (SPSS-20). Descriptive statistics like frequencies, percentages, means and standard deviations is computed. Non-parametric analysis, Chi-square test is applied and odds ratio is calculated for people with metabolic syndrome with depression and anxiety.

\section{RESULTS}

\begin{tabular}{|c|c|c|c|}
\hline \multicolumn{2}{|c|}{} & \multicolumn{2}{c|}{ Group } \\
\cline { 3 - 4 } \multicolumn{2}{|c|}{} & $\begin{array}{c}\text { Case } \\
\text { Count }\end{array}$ & $\begin{array}{c}\text { Control } \\
\text { Count }\end{array}$ \\
\hline \multirow{4}{*}{ Age } & $<35$ years & 0 & 7 \\
\cline { 2 - 4 } & $35-40$ years & 10 & 13 \\
\cline { 2 - 4 } & $40-45$ years & 20 & 14 \\
\cline { 2 - 4 } & $>45$ years & 20 & 16 \\
\hline \multirow{3}{*}{ Sex } & Male & 27 & 24 \\
\cline { 2 - 4 } & Female & 23 & 26 \\
\hline \multirow{3}{*}{ Education } & Illiterate & 9 & 9 \\
\cline { 2 - 4 } & First school & 8 & 15 \\
\cline { 2 - 4 } & Middle school & 15 & 9 \\
\cline { 2 - 4 } & High school & 13 & 10 \\
\hline
\end{tabular}

\begin{tabular}{|c|c|c|c|}
\hline & Undergraduate & 5 & 5 \\
\hline & Postgraduate & 0 & 1 \\
\hline & Professional & 0 & 1 \\
\hline \multirow{3}{*}{$\begin{array}{l}\text { Socio- } \\
\text { Economic } \\
\text { Status }\end{array}$} & Lower & 16 & 16 \\
\hline & Middle & 22 & 28 \\
\hline & Upper & 12 & 6 \\
\hline \multirow{3}{*}{ Marital } & Married & 37 & 39 \\
\hline & Married Separated & 1 & 4 \\
\hline & Widow/ Widower & 12 & 7 \\
\hline \multirow{7}{*}{ Occupation } & Profession & 10 & 8 \\
\hline & Semi Profession & 12 & 10 \\
\hline & $\begin{array}{l}\text { Farmer/Clerical/Self } \\
\text { Employed }\end{array}$ & 15 & 11 \\
\hline & Skilled & 7 & 8 \\
\hline & Semi-Skilled & 5 & 8 \\
\hline & Unskilled & 0 & 5 \\
\hline & Unemployed & 1 & 0 \\
\hline
\end{tabular}

\begin{tabular}{|c|c|c|}
\hline \multirow{4}{*}{ Disease Factors } & No. of Cases \\
\hline \multirow{4}{*}{ Age Onset } & $31-35$ years & 1 \\
\cline { 2 - 3 } & $36-40$ years & 19 \\
\cline { 2 - 3 } & $41-45$ years & 20 \\
\cline { 2 - 3 } & $46-50$ years & 10 \\
\hline \multirow{3}{*}{ Glycaemic Control } & $<5$ years & 25 \\
\cline { 2 - 3 } & $5-10$ years & 22 \\
\cline { 2 - 3 } & $>10$ years & 3 \\
\cline { 2 - 3 } & Good & 29 \\
\hline \multirow{3}{*}{ HTN Status } & Fair & 16 \\
\cline { 2 - 3 } & Poor & 5 \\
\cline { 2 - 3 } & Good & 36 \\
\cline { 2 - 3 } Complication & Fair & 11 \\
\cline { 2 - 3 } & Poor & 3 \\
\hline \multicolumn{2}{|c|}{ Table 2. Disease Factors in Cases } \\
\hline \multicolumn{2}{|c|}{ Present } \\
\hline
\end{tabular}

\begin{tabular}{|c|c|c|c|c|c|c|c|}
\hline \multicolumn{6}{|c|}{ HAMA * Group } & \multirow{3}{*}{$\begin{array}{c}\text { Chi-Square } \\
\text { Value }\end{array}$} & \multirow{3}{*}{ P-value } \\
\hline & & & \multicolumn{2}{|c|}{ Group } & \multirow{2}{*}{ Total } & & \\
\hline & & & Case & Control & & & \\
\hline \multirow{8}{*}{ HAMA } & \multirow{2}{*}{ Not Present } & Count & 33 & 45 & 78 & \multirow{10}{*}{10.989} & \multirow{10}{*}{0.012} \\
\hline & & \% within Group & $66.0 \%$ & $90.0 \%$ & $78.0 \%$ & & \\
\hline & \multirow{2}{*}{ Mild } & Count & 4 & 3 & 7 & & \\
\hline & & $\%$ within Group & $8.0 \%$ & $6.0 \%$ & $7.0 \%$ & & \\
\hline & \multirow{2}{*}{ Moderate } & Count & 6 & 2 & 8 & & \\
\hline & & $\%$ within Group & $12.0 \%$ & $4.0 \%$ & $8.0 \%$ & & \\
\hline & \multirow{2}{*}{ Severe } & Count & 7 & 0 & 7 & & \\
\hline & & $\%$ within Group & $14.0 \%$ & $0.0 \%$ & $7.0 \%$ & & \\
\hline \multirow{2}{*}{\multicolumn{2}{|c|}{ Total }} & Count & $\mathbf{5 0}$ & $\mathbf{5 0}$ & 100 & & \\
\hline & & \% within Group & $100.0 \%$ & $100.0 \%$ & $100.0 \%$ & & \\
\hline \multicolumn{8}{|c|}{ Table 3. HAM-A Distribution in Cases and Controls } \\
\hline
\end{tabular}




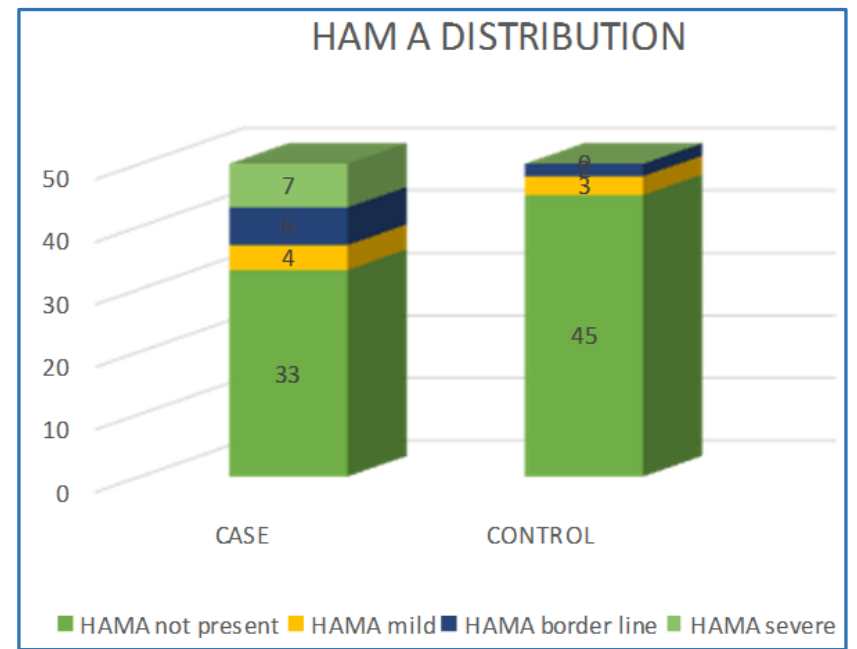

Figure 1. HAM-A Distribution in Cases and Controls
Among 50 cases by HAM-A scoring, 33 had no anxiety features; 4 had mild anxiety; 6 had borderline symptoms and 7 had severe anxiety features. Among 50 controls 45 had no anxiety features, 3 had mild symptoms and 2 had borderline anxiety features. $\mathrm{P}$ value is 0.012 and chi-square value is 10.989.

Odds ratio for anxiety is 4.636 .

\begin{tabular}{|c|c|c|c|c|c|c|c|}
\hline \multicolumn{6}{|c|}{ BDI* Group Cross Tabulation } & \multirow{3}{*}{ Chi-Square Value } & \multirow{3}{*}{ P-value } \\
\hline & & & \multicolumn{2}{|c|}{ Group } & \multirow{2}{*}{ Total } & & \\
\hline & & & Case & Control & & & \\
\hline \multirow{8}{*}{ BDI } & \multirow{2}{*}{ Normal } & Count & 30 & 43 & 73 & \multirow{10}{*}{11.715} & \multirow{10}{*}{0.008} \\
\hline & & $\%$ within Group & $60.0 \%$ & $86.0 \%$ & $73.0 \%$ & & \\
\hline & \multirow{2}{*}{ Mild } & Count & 6 & 3 & 9 & & \\
\hline & & $\%$ within Group & $12.0 \%$ & $6.0 \%$ & $9.0 \%$ & & \\
\hline & \multirow{2}{*}{ Borderline } & Count & 6 & 4 & 10 & & \\
\hline & & $\%$ within Group & $12.0 \%$ & $8.0 \%$ & $10.0 \%$ & & \\
\hline & \multirow{2}{*}{ Moderate } & Count & 8 & 0 & 8 & & \\
\hline & & $\%$ within Group & $16.0 \%$ & $0.0 \%$ & $8.0 \%$ & & \\
\hline \multirow{2}{*}{\multicolumn{2}{|c|}{ Total }} & Count & 50 & 50 & 100 & & \\
\hline & & \% within Group & $100.0 \%$ & $100.0 \%$ & $100.0 \%$ & & \\
\hline & & Table & I Distribu & Cases an & trols & & \\
\hline
\end{tabular}

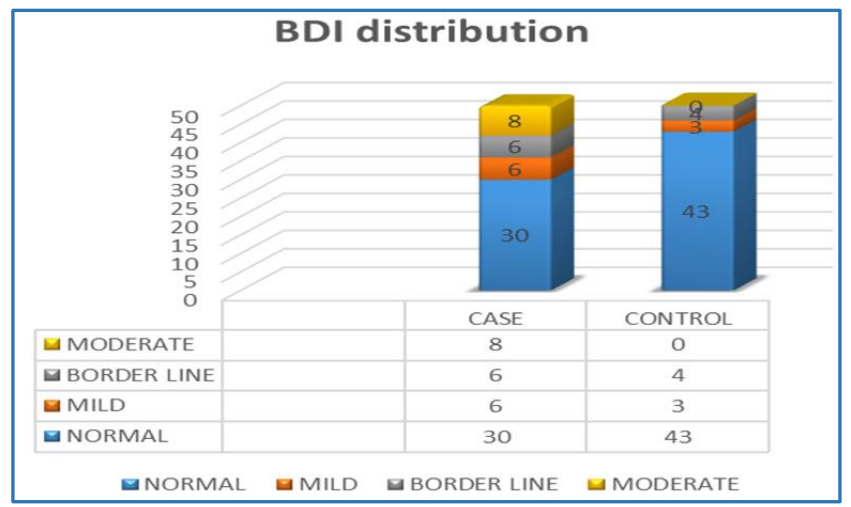

Figure 2. BDI Distribution in Cases and Controls

P- value 0.008; Pearson Chi-square 11.715; df 3

Odds ratio for depression is 4.09

Among 50 cases 20 had the symptoms of depression $(40 \%)$ and among the control group 7 individuals (14\%) had symptoms of depression in varying severity. Among 20 cases with depression 6 patients (12\%) had mild depression, 6 patients $(12 \%)$ had borderline depression and 8 patients (8\%) had moderate depression, and among 7 normal individuals 3 individuals $(6 \%)$ had mild depression, 4 individuals $(6 \%)$ had borderline depression.

\section{DISCUSSION}

In the study, the prevalence of depressive symptoms among metabolic syndrome population is $40 \%$ and in control the prevalence was $14 \%$. In patients with metabolic syndrome, depression presented with varying severity: $12 \%$ had mild depression, $12 \%$ had borderline depression, $8 \%$ had moderate depression whereas in control group 6\% had mild depression and $4 \%$ borderline depression. The Chi-square test shows a significant association with $\mathrm{p}<0.008$. This correlates with (Lestle S. Kinder, et al) 2003.(10) Odds ratio is 4.09 and it shows people with metabolic syndrome have four times more odds of getting depression.

Prevalence of depression in metabolic syndrome is up to $40 \%$. This correlates with the study of McCaffrey et al,(11) Miller et al(12) and Vogelzangs et al.(13)

This relationship between depression and metabolic syndrome is established in our study, but the direction of relationship could not be explained due to small sample size and limited focus of the study. Further, is metabolic syndrome the sole factor responsible for depression or is it a mediator or moderator is another area that could not be assessed in this study.

The current study also posits a relationship between metabolic syndrome and anxiety. Among 50 cases, 17 had the symptoms of anxiety i.e. $34 \%$ had anxiety and in the control group 5 had the symptoms of anxiety i.e. $10 \%$ had anxiety. 
In metabolic syndrome patients, anxiety presents with varying severity; $8 \%$ had mild anxiety, $12 \%$ had moderate anxiety, $14 \%$ had severe anxiety when compared to control group in which $6 \%$ had mild anxiety and $4 \%$ had moderate anxiety. The Chi-square test shows a significant association with $\mathrm{p}<0.012$. This correlates with Lillian Lopes Sharovsky et al study.(14) Odds ratio is 4.636 and it shows people with metabolic syndrome have four times more odds of getting anxiety.

The prevalence of anxiety in metabolic syndrome is higher than the control group, which correlates with the study of Van Reedt Dortland et al 2010(15) and Vreeburg et al 2010.(16) This relationship between anxiety and metabolic syndrome is established in our study, but the direction of relationship could not be explained due to small sample size and limited focus of the study.

\section{Limitations}

- Only a small number of sample (50 patients and 50 controls) participated in this study.

- The study was done at a single point of time, which prevents the episodic nature of depression and anxiety symptoms evaluation.

- This study was conducted in a tertiary care hospital, where most of the patients had severe symptoms and hence the findings of the study cannot be generalised.

- Since this study was done in a single site, the generalisability of the results is limited.

- The presence of the study among urban population limits our understanding of prevalence of depression and anxiety in metabolic syndrome among rural population.

\section{CONCLUSION}

The inferences from this study can be summarised that there is an increased prevalence of depression and anxiety in patients with metabolic syndrome than the control group. But owing to the small sample size and limited focus of the study, it cannot establish how far there is a coexistent metabolic syndrome and how far independently and collectively it contributes to psychiatric illness.

The potential implications from this study would help us to formulate treatment protocol and concentrate on the comprehensive care. Our idea of treatment of Metabolic syndrome in the presence of depression and anxiety would be drastically influenced. This leaves room for the future researches to explore these areas of association between psychiatric disorders and metabolic syndrome.

\section{REFERENCES}

[1] Citrome L. Metabolic syndrome and cardiovascular disease. J Psychopharma 2005;19(6 Suppl):84-93.
[2] Liese AD, Mayer-Davis EJ, Haffner SM. Develpoment of the multiple metabolic syndrome: an epidemiologic perspective. Epidemiol Rev 1998;20(2):157-72.

[3] Nestel P, Lyu R, Low LP, et al. Metabolic syndrome: recent prevalence in east and south east Asian population. Asian Pac J Clin Nutr 2007;16(2):362-7.

[4] Huang PL. A comprehensive definition for metabolic syndrome. Dis Model Mech 2009;2(5-6):231-7.

[5] Lustman PJ, Harper GW. Nonpsychaitric physicians identification and treatment of depression in patients with diabetes. Comprehensive Psychiatry 1987;28(1):22-7.

[6] Lustman PJ, Anderson RJ, Freedland KE, et al. Depression and poor glycemic control: a meta analytic review of literature. Diabetes Care 2000;23(7):934-42.

[7] Deepa M, Farooq S, Datta M, et al. Prevalence of metabolic syndrome using WHO, ATPIII and IDF definitions in Asian Indians: the Chennai urban rural epidemiology study (CURES-34). Diabetes Metab Res Rev 2007;23(2):127-34.

[8] Beck AT, Ward CH, Mendelson M, et al. An inventory for measuring depression. Arch Gen Psychiatry 1961;4:561-71.

[9] Hamilton M. The assessment of anxiety states by rating. Br J Med Psychol 1959;32(1):50-5.

[10] Kinder LS, Carnethon MR, Palaniappan LP, et al. Depression and the metabolic syndrome in young adults: findings from the third national health and nutrition examination survey. Psychosom Med 2004;66(3):316-22.

[11] McCaffery JM, Niaura R, Todaro JF, et al. Depressive symptoms and metabolic risk in adult male twins enrolled in the national heart, lung, and blood institute twin study. Psychosom Med 2003;65(3):490-7.

[12] Miller GE, Freedland KE, Carney RM, et al. Pathways linking depression, adiposity, and inflammatory markers in healthy young adults. Brain Behav Immun 2003;17(4):276-85.

[13] Vogelzangs N, Suthers K, Ferrucci L, et al. Hypercortisolemic depression is associated with the metabolic syndrome in late-life. Psychoneuroendocrinology 2007;32(2):151-9.

[14] Sharovsky LL, Romano BW. Depressive and anxiety symptoms in patients with metabolic syndrome. Estudos de Psicologia Campinas 2013;30(4):603-8.

[15] Van Reedt Dortland AK, Giltay EJ, Van Veen T, et al. Metabolic syndrome abnormalities are associated with severity of anxiety and depression and with tricyclic antidepressant use. Acta Psychiatr Scand 2010;122(1):30-9.

[16] Vreeburg SA, Hartman CA, Hoogendijk WJ, et al. Parental history of depression or anxiety and the cortisol awakening response. $\mathrm{Br} \mathrm{J}$ Psychiatry 2010;197(3):180-5. 